\title{
Technique of Echographic Examination of Right Ventricular Wall Thickness from the Right Sternal Border
}

\author{
Sonia Chang, B.A., Susan Roberts, John K. Chang, B.A., \\ Martha Kleinberg, M.D., and Ramon Rodriquez-Torres, M.D.
}

\section{Summary}

Right ventricular wall motion was readily accessible for echocardiographic recording along the right sternal border in 27 pediatric patients (age: $24 \mathrm{hrs}-12 \mathrm{yrs}$ ). Right ventricular epicardial and endocardial wall motion could be recorded only at the right sternal border in 10 of these patients, emphasizing the need for a new, alternative examination site.

Calculated measurements of right ventricular wall thickness recorded from both right and left sternal borders $(7 \mathrm{pts}$ ) were similar (range of diff. $=0-0.6 \mathrm{~mm}$; mean of $\operatorname{diff} .=0.26 \mathrm{~mm}$ ). Autopsy confirmation of right ventricular wall thickness was obtained in 2 patients.

Epicardial motion could not be identified at the left sternal border in 10 patients. In these patients, right ventricular wall thickness was estimated by measuring from the inner chest wall to the endocardium. These measurements were compared to right ventricular wall thickness obtained from the right sternal border. Wall thickness obtained from the left sternal border was significantly underestimated in the absence of a definite epicardial interface (range of diff. $=0.2-2.6 \mathrm{~mm}$; mean of diff. $=1.3 \mathrm{~mm}$ ).

We conclude that the right sternal border is a useful examination site when studies from the left sternal border are technically inadequate for evaluation. Measurement of right ventricular wall thickness should not be attempted unless both epicardial and endocardial interfaces are recorded simultaneously.

\section{Additional Indexing Words :}

Echocardiography Right ventricle Epicardium Endocardium

ECENT correlations of echographic right ventricular wall thickness accurate method to determine right ventricular wall thickness. Traditionally,

From the Departments of Pediatrics and Medicine, Medical College of Ohio at Toledo, Toledo, Ohio; and Riverside Hospital, Toledo, Ohio.

Address for reprints: Sonia Chang, Assistant Professor of Medicine, Room 332, Department of Medicine, Medical College of Ohio, C. S. 10008, Toledo, Ohio 43699, U.S.A.

Received for publication January 26, 1979. 
echocardiographic right ventricular wall thickness has been obtained from the left parasternum or through the sternum in the pediatric patient. ${ }^{3-5}$ ) When unable to record technically acceptable right ventricular epicardial and endocardial motion at the left sternal border, we have found this motion to be readily accessible for recording from the right parasternum. We present our examination technique and observations concerning the thickness and mobility characteristics of the right ventricular wall when recorded along the right sternal border.

\section{METHODS}

Patient selection:

Twenty-seven patients were selected for this series based upon the availability of technically satisfactory right ventricular wall echocardiograms from the right sternal border. In the first 17 patients, this type of examination was deliberately initiated for comparative studies of right ventricular wall thickness and motion from both right and left sternal borders. In the last 10 patients, it was necessary to use the right sternal border as an examination site due to rightward cardiac rotation and/or displacement.

Patient age ranged from 24 hours to 12 years. Six children were without clinical evidence of cardiovascular disease. Twenty-one patients had congenital heart disease, 13 of whom were referred for cardiac catheterization within 48 hours after echographic examination.

\section{Instrumentation:}

Echocardiograms were recorded with a Smith-Kline Ekoline $20 \mathrm{~A}$ ultrasonoscope interfaced with a Honeywell $1856 \mathrm{~A}$ ultraviolet visicorder. Patients under the age of 3 years were examined with an Aerotech 5.0 megaHertz $(\mathrm{MHz}), 0.25$ inch, nonfocused transducer. The ultrasonoscope was switched to $3-6 \mathrm{MHz}$ to match the frequency response of the transducer being uscd. For older children, a 0.25 inch, $3.25 \mathrm{MHz}$ (nonfocused) or $2.25 \mathrm{MHz}$ transducer (medium focus) was utilized. The ultrasonoscope was set at $1-3 \mathrm{MHz}$ to match these lower frequency transducers.

Examinations of most infants were performed without the use of depth compensation (time-gain-compensation). Infants with dilated right ventricles, and children above the age of 2 years with more developed right ventricular cavities allowed use of depth compensation. Signals returned from the chest wall and right ventricular wall could thus be amplified or suppressed without altering the amplification of echographic signals returned from the atrioventricular valves and interventricular septum.

Measurement of wall thickness was facilitated when the tracing was expanded; however, overexpansion resulted in some undesirable loss of signal resolution. Paper recording speed varied from $25 \mathrm{~mm} / \mathrm{sec}$ to $100 \mathrm{~mm} / \mathrm{sec}$. Optimal recording speed was $50 \mathrm{~mm} / \mathrm{sec}$.

\section{Technique of patient examination:}

Right ventricular epicardial and endocardial interfaces could be recorded at 


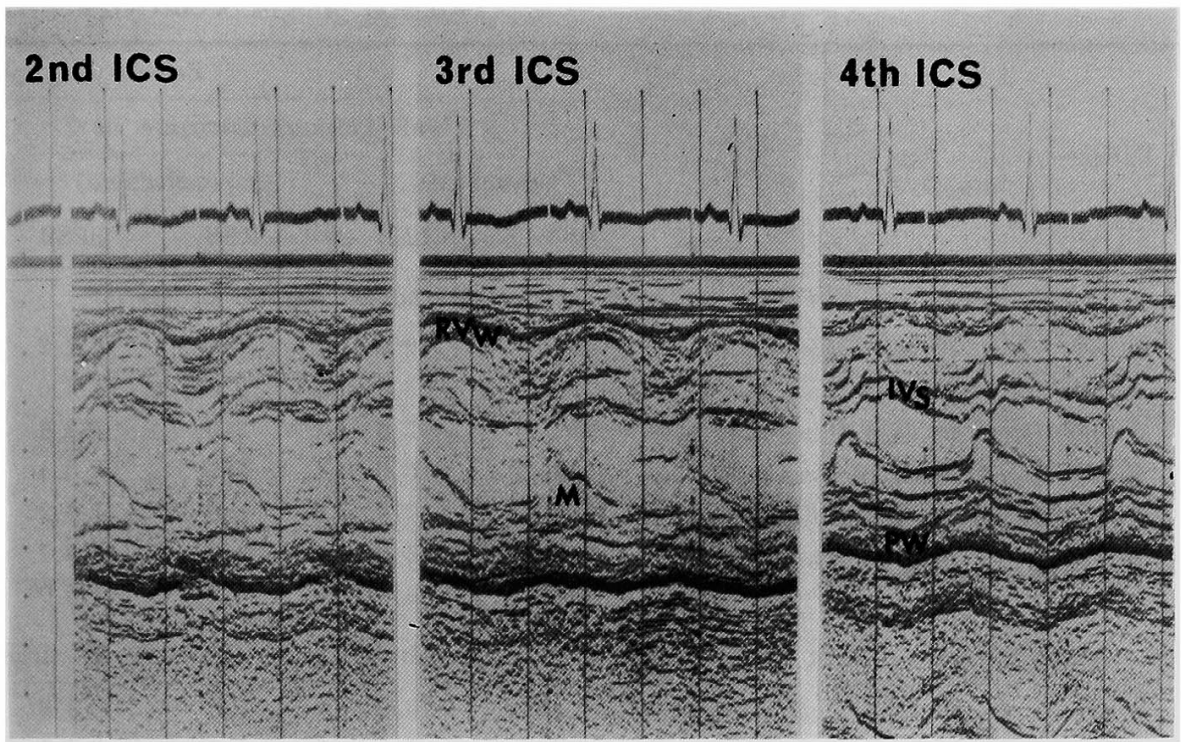

Fig. 1. (Table I, Case 20). Right ventricular wall motion and thickness recorded from 3 right intercostal spaces. Optimal recording suitable for measurement of wall motion and thickness was obtained from the third right intercostal spece. ICS = intercostal space ; IVS=interventricular septum ; $M=$ mitral valve; $\mathrm{PW}=$ posterior left ventricular wall ; $\mathrm{P} . \mathrm{VW}=$ right ventricular wall.

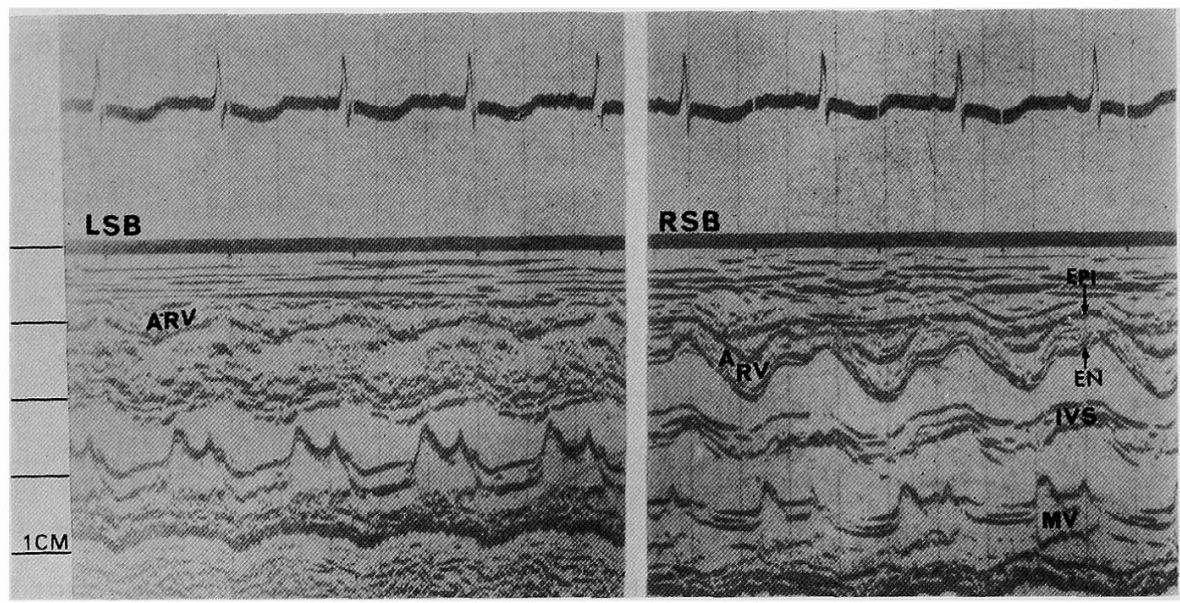

Fig. 2. Male, age $15 \mathrm{mo}$, normal. Representative tresentative tracing demonstrating right ventricular wall thickness and mobility when epicardial and endocardial interfaces could be recorded from both right and left sternal borders. $A R V=$ anterior right ventricular wall ; IVS =interventricular septum ; $\mathrm{EN}=$ endocardial interface $; \mathrm{EPI}=$ epicardial interface $; \mathrm{LSB}=$ left sternal border ; $\mathrm{MV}=$ mitral valve ; $\mathrm{RSB}=$ right sternal border. 
Table I. Right Ventricular Wall

\begin{tabular}{l|l|c|c|c|}
\hline \multirow{3}{*}{ Patient } & \multirow{3}{*}{ Age } & BSA & \multicolumn{2}{|c|}{ Echocardiographic } \\
& & $\left(\mathrm{M}^{2}\right)$ & \multicolumn{2}{|c|}{ Wall Thickness (mm) } \\
\hline
\end{tabular}

(A) Endocardial and epicardial motion recorded at right and left sternal borders

\begin{tabular}{|c|c|c|c|c|c|c|}
\hline 1-BW & $72 \mathrm{hrs}$ & 0.20 & 2.0 & 2.0 & 2.4 & 2.3 \\
\hline $2 \mathrm{MR}$ & 21 days & 0.19 & 3.0 & 3.0 & 2.6 & 2.6 \\
\hline 3-MS* & 49 days & 0.23 & 3.0 & 2.0 & 3.0 & 2.4 \\
\hline $4-\mathrm{AM}$ & $10 \mathrm{mo}$ & 0.32 & 6.0 & 6.0 & 6.7 & 6.4 \\
\hline $5-S J^{* *}$ & $3 \mathrm{yrs}$ & 0.69 & 7.0 & 7.0 & 6.0 & 6.2 \\
\hline 6-SG & 4 yrs & 0.77 & 3.5 & 3.0 & 3.9 & 3.7 \\
\hline 7-MS & 5 yrs & 0.66 & 5.0 & 5.0 & 5.4 & 5.0 \\
\hline
\end{tabular}

(B) Epicardium seen at right sternal border only; endocardium seen at right and left sternal

\begin{tabular}{|c|r|r|l|l|l|l|}
\hline $8-\mathrm{BH}$ & $24 \mathrm{hrs}$ & 0.18 & 5.0 & 3.0 & 6.2 & 3.6 \\
$9-\mathrm{BA}$ & $96 \mathrm{hrs}$ & 0.19 & 3.0 & 2.0 & 3.2 & 3.0 \\
$10-\mathrm{JP}$ & $2 \mathrm{mo}$ & 0.30 & 3.0 & 2.0 & 3.6 & 2.6 \\
$11-\mathrm{JK}$ & $5 \mathrm{mo}$ & 0.24 & 3.5 & 2.0 & 3.8 & 3.3 \\
$12-\mathrm{MR}$ & $13 \mathrm{mo}$ & 0.38 & 5.0 & 4.0 & 4.1 & 3.3 \\
$13-\mathrm{MD}$ & $13 \mathrm{mo}$ & 0.46 & 6.0 & 6.0 & 6.5 & 5.4 \\
$14-\mathrm{MD}$ & $5 \mathrm{yrs}$ & 0.82 & 4.0 & 3.0 & 3.7 & 3.1 \\
$15-\mathrm{CH}$ & $6 \mathrm{yrs}$ & 0.68 & 4.0 & 3.0 & 5.3 & 3.5 \\
$16-\mathrm{RW}$ & $6 \mathrm{yrs}$ & 0.81 & 5.0 & 3.0 & 5.1 & 3.0 \\
$17-\mathrm{JW}$ & $12 \mathrm{yrs}$ & 1.34 & 8.0 & 7.0 & 7.6 & 5.6
\end{tabular}

(C) Epicardium and endocardium seen at right sternal border only

\begin{tabular}{l|c|c|c|c|c|c|}
\hline $18-\mathrm{HT}$ & $30 \mathrm{days}$ & 0.26 & 3.0 & - & 3.8 & - \\
$19-\mathrm{RG}$ & 35 days & 0.23 & 4.0 & - & 3.9 & - \\
$20-\mathrm{MM}$ & $4 \mathrm{mo}$ & 0.27 & 4.0 & - & 4.3 & - \\
$21-\mathrm{TH}$ & $5 \mathrm{mo}$ & 0.28 & 3.5 & - & 3.6 & - \\
$22-\mathrm{RB}$ & $10 \mathrm{mo}$ & 0.24 & 4.5 & - & 5.6 & - \\
$23-\mathrm{CC}$ & $5 \mathrm{yrs}$ & 0.77 & 5.0 & - & 4.9 & - \\
$24-\mathrm{DM}$ & $5 \mathrm{yrs}$ & 0.82 & 3.5 & - & 4.3 & - \\
$25-\mathrm{SP}$ & $7 \mathrm{yrs}$ & 0.88 & 5.0 & - & 5.7 & - \\
$26-\mathrm{DD}$ & $10 \mathrm{yrs}$ & 0.76 & 6.5 & - & 5.7 & - \\
$27-\mathrm{GF}$ & $11 \mathrm{yrs}$ & 1.23 & 4.0 & - & 4.4 & -
\end{tabular}

* expired at home; right ventricular wall thickness at autopsy was $2 \mathrm{~mm}$.

** expired post op ECD repair; right ventricular wall thickness at autopsy was $6 \mathrm{~mm}$.

Abbreviations: BSA $\left(\mathrm{M}^{2}\right)=$ body surface area expressed in square meters; RSB = right sternal border; $\mathrm{LSB}=$ left sternal border; $\mathrm{RV}_{\mathrm{p}}=$ right ventricular pressure; $\mathrm{NC}=$ no catheterization; 
Thickness by Echocardiography

\begin{tabular}{|c|c|c|c|}
\hline \multicolumn{2}{|l|}{ Data } & \multicolumn{2}{|c|}{ Clinical/Catheterization Data } \\
\hline \multicolumn{2}{|c|}{ Wall Amplitude (mm) } & \multirow{3}{*}{$\underset{(\mathrm{mmHg})}{\mathrm{RV}_{\mathrm{p}}}$} & \multirow{3}{*}{ Dlagnosis } \\
\hline \multicolumn{2}{|c|}{ (calculated) } & & \\
\hline RSB & LSB & & \\
\hline 1.8 & 1.9 & $\mathrm{NC}$ & Normal \\
\hline 2.7 & 2.3 & $\mathrm{NC}$ & Normal \\
\hline 4.2 & 1.0 & $\mathrm{NC}$ & Normal \\
\hline 5.7 & 7.3 & $92 / 0$ & Taussig-Bing Syndrome \\
\hline 4.1 & 4.8 & $88 / 8$ & ECD; PA banding, age 1 yr \\
\hline 4.0 & 3.5 & $\mathrm{NC}$ & AS, mild; congenital \\
\hline 5.4 & 3.4 & $67 / 9$ & PS \\
\hline \multicolumn{4}{|l|}{ border } \\
\hline 4.6 & 5.2 & $51 / 10$ & $\mathrm{ECD}$ \\
\hline 3.8 & 2.5 & $\mathrm{NC}$ & Normal \\
\hline 4.8 & 4.1 & $\mathrm{NC}$ & VSD \\
\hline 3.1 & 1.3 & $22 / 9$ & PDA \\
\hline 6.3 & 4.9 & $24 / 4$ & PDA \\
\hline 5.9 & 3.8 & $106 / 18$ & $\mathrm{VSD}+\mathrm{PS}$ \\
\hline 6.1 & 3.3 & $\mathrm{NC}$ & AS, mild; congenital \\
\hline 4.9 & 4.2 & $23 / 4$ & Coarctation of aorta \\
\hline 6.0 & 4.1 & $30 / 4$ & PS \\
\hline 6.8 & 4.9 & $84 / 7$ & PS \\
\hline 1.9 & - & $\mathrm{NC}$ & VSD \\
\hline 4.8 & - & $\mathrm{NC}$ & VSD \\
\hline 9.4 & - & NC & $V S D+P S$ \\
\hline 2.2 & - & $107 / 5$ & TGA, VSD, ASD \\
\hline 3.8 & - & $89 / 7$ & VSD, IPS, PS, ASD \\
\hline 3.9 & - & $\mathrm{NC}$ & Cardiomyopathy \\
\hline 7.1 & - & $\mathrm{NC}$ & Normal \\
\hline 3.4 & - & NO & ASD, post op; PE \\
\hline 3.5 & - & $\mathrm{NC}$ & VSD \\
\hline 6.1 & - & $\mathrm{NC}$ & Normal \\
\hline
\end{tabular}

$\mathrm{NO}=$ right ventricular pressure was not obtained during catheterization; $\mathrm{ECD}=$ endocardial cushion defect; $\mathrm{PA}=$ pulmonary artery; $\mathrm{AS}=$ aortic stenosis; $\mathrm{PS}=$ pulmonic stenosis ; $\mathrm{VSD}=$ ventricular septal defect; TGA = transposition of great arteries; $A S D=$ atrial septal defect ; PE = pericardial effusion; IPS =infundibular pulmonic stenosis. 
the right sternal border from recumbent infants or very young children. Older children, usually exceeding 3 years of age, were more easily examined when the heart was rotated toward the right sternum. This was accomplished by turning the patient toward a partial or steep right lateral decubitus position. A pillow tucked behind the child's back aided patient comfort and stability. The subxiphoid approach $^{6}$ ) was either not attempted or was unsuccessful in these children.

The transducer was located along the right sternal border and was directed medially toward the tricuspid valve or mitral valve with a minimum of superior or inferior angulation. In each patient, the right ventricular wall was examined from several right intercostal spaces to locate maximum systolic amplitude and minimal wall thickness ${ }^{7)}$ (Fig. 1). Frequently, there was a slight systolic separation of the epicardium from the inner chest wall. This separation between a stationary structure (chest wall) and a dynamic structure (anterior right ventricular wall) was not considered representative of anterior pericardial effusion in the absence of other clinical or echocardiographic findings. ${ }^{8}$ In fact, this slight separation assisted in the identification of the epicardial surface of the right ventricular wall from the inner chest wall.

Right ventricular wall measurement:

Diastolic right ventricular wall thickness was measured from the top of the epicardial echo to the top of the endocardial echo at the onset of the electrocardiographic " $Q$ " wave; or at the onset of the QRS when a definite " $Q$ " was not available (Fig. 2).

Right ventricular wall thickness was measured from the original tracings on 2 separate occasions. The first measurement was an estimation of wall thickness as compared to electronically recorded calibration points. Several months later, the wall thickness was calculated by re-measuring the distance between the epicardial and endocardial interfaces with very fine-pointed calipers. Measurements were read on a surgical ruler to the nearest $0.25 \mathrm{~mm}$. This measurement was then divided by the distance between 2 calibration points read to the nearest 0.25 $\mathrm{mm}$ on the same ruler. For each patient, 4 or 5 sequential measurements were obtained and averaged. The averaged wall thickness measurement was accepted as representative of the anterior right ventricular wall thickness. This data is presented in Table $I$.

To test the reproducibility of the measurement method, the right ventricular wall thickness of 7 patients (Table I : A) was recalculated from the original tracings several months after the initial, calculated measurements were obtained. Comparison of differences between 68 individual measurements of wall thickness on 2 separate trials ranged from $0.0-0.8 \mathrm{~mm}$ with a mean difference of $0.26 \mathrm{~mm}$ (Table II). All measurements in this study were performed by the same observer (the author).

\section{ObSERVATIONS}

Right ventricular wall thickness:

Epicardial and endocardial interfaces could be recorded from both right and left sternal border in 7 patients (Table I: A). In each case, the right 
$\begin{array}{ll}\text { Vol. } 20 & \text { RIGHT VENTRICULAR WALL THICKNESS IN ECHOCARDIOGRAM } \\ \text { No. } 3 & 3\end{array}$

Table II. Reproducibility of Calculated Right Ventricular Wall Thickness Measurements

\begin{tabular}{|c|c|c|c|c|}
\hline \multirow{2}{*}{ Patient } & \multirow{2}{*}{ Sample } & \multicolumn{2}{|c|}{ Right Ventricular Wall Thickness (mm) } & \multirow{2}{*}{ Diff. (mm) } \\
\hline & & Trial 1 & Trial 2 & \\
\hline \multirow[t]{5}{*}{$1-B W$} & 1 & 2.6 & 2.7 & 0.1 \\
\hline & 2 & 2.6 & 2.7 & 0.1 \\
\hline & 3 & 2.3 & 2.5 & 0.2 \\
\hline & 4 & 2.3 & 2.6 & 0.3 \\
\hline & 5 & 2.0 & 2.5 & 0.5 \\
\hline \multirow[t]{5}{*}{$2-M R$} & 1 & 2.6 & 2.6 & 0 \\
\hline & 2 & 2.6 & 2.1 & 0.5 \\
\hline & 3 & 2.8 & 2.6 & 0.2 \\
\hline & 4 & 2.6 & 2.3 & 0.3 \\
\hline & 5 & 2.6 & 2.6 & 0 \\
\hline \multirow[t]{5}{*}{ 3-MS } & 1 & 2.8 & 2.8 & 0 \\
\hline & 2 & 3.3 & 3.3 & 0 \\
\hline & 3 & 2.5 & 2.5 & 0 \\
\hline & 4 & 3.1 & 3.1 & 0 \\
\hline & 5 & 3.1 & 3.1 & 0 \\
\hline \multirow[t]{4}{*}{$4-A M$} & 1 & 6.5 & 6.4 & 0.1 \\
\hline & 2 & 7.0 & 7.3 & 0.3 \\
\hline & 3 & 6.5 & 7.3 & 0.8 \\
\hline & 4 & 6.7 & 7.5 & 0.8 \\
\hline \multirow[t]{5}{*}{$5-\mathrm{S} J$} & 1 & 5.3 & 5.3 & 0 \\
\hline & 2 & 6.4 & 6.6 & 0.2 \\
\hline & 3 & 5.8 & 6.4 & 0.6 \\
\hline & 4 & 6.7 & 6.6 & 0.1 \\
\hline & 5 & 5.6 & 6.4 & 0.8 \\
\hline \multirow[t]{5}{*}{$6-\mathrm{SG}$} & 1 & 3.0 & 3.7 & 0.7 \\
\hline & 2 & 4.4 & 4.4 & 0 \\
\hline & 3 & 4.4 & 4.1 & 0.3 \\
\hline & 4 & 3.3 & 3.0 & 0.3 \\
\hline & 5 & 4.4 & 4.1 & 0.3 \\
\hline \multirow[t]{5}{*}{ 7-MS } & 1 & 6.4 & 6.0 & 0.4 \\
\hline & 2 & 4.8 & 4.8 & 0 \\
\hline & 3 & 5.2 & 5.2 & 0 \\
\hline & 4 & 5.2 & 4.8 & 0.4 \\
\hline & 5 & 5.2 & 5.2 & 0 \\
\hline
\end{tabular}

Range of differences between Trial 1 and Trial 2 measurements $=0.0-0.8 \mathrm{~mm}$.

Mean of differences $=0.26 \mathrm{~mm}$. 
Endo- and Epi- Seen RSB and LSB

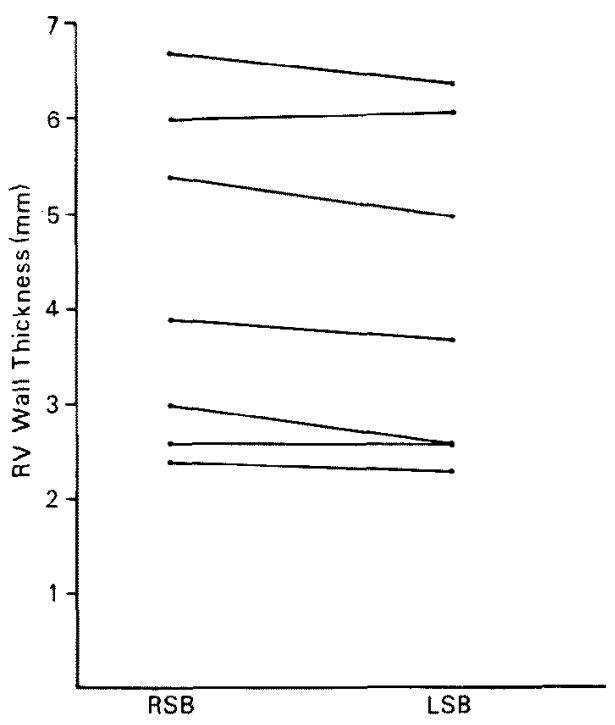

Fig. 3. (Table I : A). Comparison of right and left ventricular wall thickness when epicardial and endocardial interfaces could be recorded at both right and left sternal borders. Endo=endocardium; Epi=epicardium; $\mathrm{LSB}=$ left sternal border; $\mathrm{RSB}=$ right sternal border; $\mathrm{RV}=$ right ventricle.

ventricular wall thickness was slightly less at the left sternal border (Fig. 3). The range of differences between averaged, calculated measurements of wall thickness at the right and left sternal borders was $0.1-0.6 \mathrm{~mm}$ with a mean difference of $0.26 \mathrm{~mm}$.

In 10 patients, the epicardial interface was not evident at the left sternal border, but was clearly demarcated along the right sternal border (Table I: B). In these 10 cases, the right ventricular wall thickness at the left sternal border was estimated by measuring from the inner chest wall to the endocadial interface. In every case, the wall thickness was significantly underestimated when compared to right ventricular wall thickness obtained along the right sternal border (Fig. 4). The difference between averaged, calculated wall thickness at the right and left sternal borders ranged from 0.2 to $2.6 \mathrm{~mm}$ with a mean difference of $1.3 \mathrm{~mm}$.

Epicardial and endocardial interfaces could not be recorded at the left sternal border nor through the sternum in 10 children regardless of transducer or patient position (Table I: $\mathrm{C}$ ). The right sternal border was utilized successfully as an examination site. These 10 children, 8 with cardiovascular abnormalities affecting the right heart, emphasized the need for an alternative method for right ventricular wall examination. 


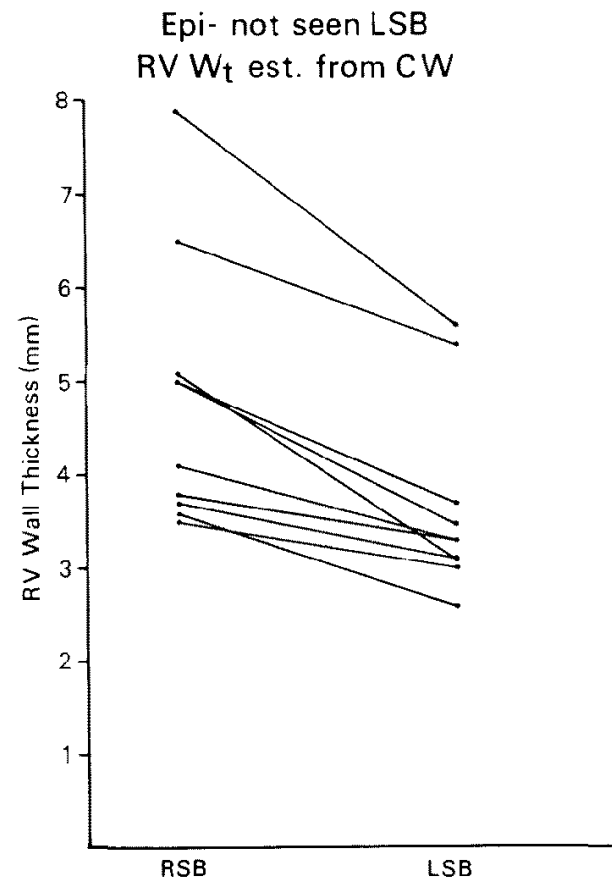

Fig. 4. (Table I: B). Underestimation of right ventricular wall thickness at left sternal border when epicardial interface could not be recorded. Underestimation of wall thickness resulted from estimation of wall thickness when measured from inner chest wall to endocardial interface. CW=chest wall; Epi=epicardium ; est = estimated $\mathrm{RV}=$ right ventricle $; \mathrm{RVW}_{\mathrm{t}}=$ right ventricular wall thickness; $\mathrm{LSB}=$ left sternal border; $\mathrm{RSB}=$ right sternal border.

\section{Systolic wall excursion:}

Right ventricular endocardial interfaces were identified at both right and left sternal borders in 17/27 patients (Table I: A, B). Thus, right ventricular wall systolic excursion from both examination sites could be compared. Excursion was defined as the perpendicular displacement of the right ventricular wall away from the chest wall during systole. The onset of posterior displacement was measured at the onset of the electrocardiographic " $Q$ " wave; or at the onset of the QRS when the " $Q$ " was absent. The termination of posterior displacement was identified from (1) the end of ventricular repolarization on the electrocardiogram; (2) the onset of the second heart sound; and/or (3) the maximum posterior displacement of the right ventricular wall.

With the exccption of 4 patients (Cascs 1, 4, 5, 8), the systolic excursion of the right ventricular wall was greater when recorded at the right sternal border. Three of the 4 patients with greater wall excurision at the left sternal 
border had significant right ventricular volume overloads. One patient (Case 1), did not have cardiovascular disease. The excursion was only slightly greater at the left sternal border.

Autopsy confirmation:

A 35-day-old infant was examined with echocardiography following an episode of "blueness" during feeding (Table I, Case 3). No further episodes of "blueness" occurred during the patient's hospitalization and he was discharged. At the age of 49 days, the patient expired at home.

Necropsy examination was essentially unremarkable. The thoracic organs were preserved in $10 \%$ formalin for 18 days prior to wall measurement. A pathologist, having no knowledge of the echocardiographic results, measured the anterior right ventricular wall thickness at the most proximal aspect of the right ventricular infundibulum. In addition, the lateral right ventricular wall was measured at the level of the tricuspid valve. Excluding trabeculations, the right ventricular wall thickness measured $2.0 \mathrm{~mm}$ at both anatomic locations. Prior to death, the echographic wall thickness measured $3.0 \mathrm{~mm}$ at the right sternal border and $2.4 \mathrm{~mm}$ at the left sternal border. The discrepancy between the echographic and autopsy measurements could have been due to lack of myocardial perfusion and to cellular dehydration.

The second child expired 13 days after repair of a complete endocardial cushion defect (Table I, Case 5). Necropsy examination of the fresh heart disclosed an anterior wall thickness of $6.0 \mathrm{~mm}$ at the most proximal aspect of the right ventricular infundibulum. This measurement was comparable to the echographic thickness obtained before and after surgical intervention. The lateral right ventricular wall thickness measured $13 \mathrm{~mm}$ at necropsy. Trabeculations were excluded from all measurements. Wall thickness of this magnitude was never recorded at either sternal border before or following surgery.

\section{Comment}

Historical data ${ }^{31-5), 9)-12)}$ suggests that normal right ventricular wall thickness ranges from 2.0 to $5.0 \mathrm{~mm}$, averaging $3.0 \mathrm{~mm}$. Ages ranged from 1 month to adolescenece. In our study, we found 6 normal individuals demonstrating right ventricular wall thickness ranging from 2.3 to $4.4 \mathrm{~mm}$. Ages ranged from 72 hours to 11 years (Table I, Cases 1-3, 9, 24, 27). In 2 of these children, echographic right ventricular wall thickness was achieved only at the right sternal border (Table I, Cases 24, 27).

If myocardial thickening is progressive in response to chronic pressure 
overload as previously described, ${ }^{13}$ it may be potentially identified with echocardiography. Identification requires technically correct, serial echocardiographic studies which have been measured with exquisite care. We have demonstrated significant underestimation of the right ventricular wall thickness when the epicardial interface is not recorded. Thus, echocardiographic right ventricular wall thickness should not be measured unless both epicardial and endocardial interfaces are recorded simultaneously. The right sternal border examination has proved to be an attractive alternative method to obtain technically acceptable echographic tracings of right ventricular wall thickness and excursion when records cannot be achieved from left sternal border or subxiphoid examination sites.

\section{REFERENCES}

1. Arcilla $R$, Mathew $R$, Sodt $P$, Lester L, Cahill $N$, Thilenius $O$ : Right ventricular mass estimation by angioechocardiography. Cath \& Cardiovasc Diag 2: 125, 1976

2. Prakash $R$, Lindsay $P$ : Determination of right ventricular wall thickness by echocardiogram. JAMA 239: 638, 1978

3. Hagan A, Deely W, Sahn D: Echocardiographic criteria for normal newborn infants. Circulation 48: 1221,1973

4. Solinger R, Elbl F, Minhas K: Echocardiography in the normal neonate. Circulation 47: 108,1973

5. Epstein ML, Goldberg SJ, Allen HD, Konecke L, Wood J: Great vessel, cardiac chamber and wall growth patterns in normal children. Circulation 51: 1124, 1975

6. Chang S: M-Mode Echocardiographic Techniques and Pattern Recognition. Lea \& Febiger, Philadelphia, 1976

7. Meyer R: Pediatric Echocardiography. Lea \& Febiger, Philadelphia, p13-20, 1977

8. Feigenbaum H: Echocardiography, 2nd ed, Lea \& Febiger, Philadelphia, p 427, 1976

9. de la Cruz M, Anselmi G, Romero A, Monroy G: A qualitative and quantitative study of the ventricles and great vessels of normal children. Am Heart J 60: 675, 1960

10. Schulz D, Giordano D: Hearts of infants and children. Arch Path 74: 464, 1962

11. Rowlatt $\mathbf{U}$, Rimoldi H, Lev M: The quantitative anatomy of the normal child's heart. Pediat Clin N Am 10: 499, 1963

12. Eckner F, Brown B, Davidson D, et al: Dimensions of normal human hearts. Arch Path 88: 497,1967

13. Gewitz M, Eshaghpour E, Holsclaw D, Miller H, Kawai N: Echocardiography in cystic fibrosis. Circulation 50 (Suppl 3): 16, 1974 (abstr) 